Article

\title{
Precipitates in Compact Strip Production (CSP) Process Non-Oriented Electrical Steel
}

\author{
Jia-long Qiao ${ }^{1, * \mathbb{C}}$, Fei-hu Guo ${ }^{1}$, Jin-wen Hu ${ }^{1,2}$, Li Xiang ${ }^{1}$, Sheng-tao Qiu ${ }^{1}$ and Hai-jun Wang ${ }^{2}$ \\ 1 National Engineering Research Center of Continuous Casting Technology, China Iron \& Steel Research \\ Institute Group, Beijing 100081, China; guofeihu2020@163.com (F.-h.G.); hjw1328849503@163.com (J.-w.H.); \\ cyzchina@126.com (L.X.); qiustchina@126.com (S.-t.Q.) \\ 2 School of Metallurgy and Resources, Anhui University of Technology, Maanshan 243002, China; \\ whjchina@ahut.edu.cn \\ * Correspondence: qiaojialong2015@126.com; Tel.: +86-188-0102-8675
}

Received: 16 July 2020; Accepted: 18 September 2020; Published: 29 September 2020

check for updates

\begin{abstract}
Nitrogen and Sulfur in non-oriented electrical steel would form precipitates, which would severely affect its magnetic properties. Precipitates in compact strip production (CSP) process non-oriented electrical steel were investigated using a transmission electron microscope (TEM) and scanning electron microscopy (SEM). The precipitation mechanism and influence on grain growth were analyzed experimentally and theoretically. The results showed that the main particles in steel were $\mathrm{AlN}, \mathrm{TiN}, \mathrm{MnS}, \mathrm{Cu}_{2} \mathrm{~S}$, and fine oxide inclusions. The spherical or quasi-spherical of $\mathrm{MnS}$ and $\mathrm{Cu}_{2} \mathrm{~S}$ were more liable to precipitate along grain boundaries. During the soaking process, the amount of MnS precipitated on the grain boundary was much larger than that of $\mathrm{Cu}_{2} \mathrm{~S}$. AlN and TiN in cubic shape precipitated inside grains or grain boundaries. Precipitates preferentially nucleated at grain boundaries, and $\mathrm{TiN}, \mathrm{MnS}$ mainly precipitated during soaking. In the subsequent processes after soaking, $\mathrm{AlN}$ and $\mathrm{Cu}_{2} \mathrm{~S}$ would precipitate unceasingly with the decrease in the average size. The distribution density, the volume fraction, and the average size of the precipitates in the annealed sheets were $9.08 \times 10^{13} / \mathrm{cm}^{3}, 0.06 \%$, and $54.3 \mathrm{~nm}$, respectively. Precipitates with the grain size of $30-500 \mathrm{~nm}$ hindered the grain growth, the grains with 100-300 $\mathrm{nm}$ played a major role in inhibiting the grain growth, and the grains with the grain size of 70-100 $\mathrm{nm}$ took the second place.
\end{abstract}

Keywords: non-oriented electrical steel; CSP process; magnetic properties; precipitates; particle growth; driving force and pinning force

\section{Introduction}

Non-oriented electrical steel is a kind of soft magnetic alloys, which desire high magnetic induction and low core loss [1]. On account of the small columnar crystals, which belong to the cubic texture $(\{100\}<001>)$ of continuous cast slab that would inherit to the finished product, the magnetic induction intensity of compact strip production (CSP) process non-oriented electrical steels would be higher than the traditional products. However, the magnetic properties would be deteriorated by inclusions, which are difficult to float during the casting process, and the small size of precipitates through inhibiting grain growth [2-7].

As a result of the solubility fall of certain elements, the major residual elements or impurities of $\mathrm{Cu}, \mathrm{Ti}, \mathrm{S}, \mathrm{N}$, etc. would form nitride and sulfide precipitates [8]. $\mathrm{AlN}, \mathrm{TiN}, \mathrm{MnS}, \mathrm{Cu}_{2} \mathrm{~S}$, etc. would obviously hinder the growth of crystal grains and strengthen $\gamma$-fiber texture components, leading to the decrease of magnetic properties of non-oriented electrical steel $[1,5,9,10]$.

Many research works have been reported on the study of nitride and sulfide precipitates' precipitation mechanism in non-oriented electrical steel [5-7,9-14]. The particle nucleation rate and 
growth depend on the nucleation driving force, the diffusivity of controlling element $\mathrm{M}$ in the matrix, and the interfacial energy associated with the matrix $[8,15]$. In the CSP process' non-oriented electrical steel, the size of precipitates would grow more in the soaking process, but the precipitation contents are less [5].

Meanwhile, models on the grain growth inhibition by precipitates are presented with the hypotheses that the grain growth will stop by the pinning force of particles [12-14,16,17]. Studies show that the relationship between grain sizes would be strongly inhibited by increasing the interfacial area between grains and particles [18-20]. The effect of different size of precipitates on the ferrite grain growth is also different in non-oriented electrical steel [7,10,14,21-26].

Given the above, the precipitation mechanism of precipitates in the CSP process' non-oriented electrical steel has not been studied comprehensively, and most of these studies only simulate the qualitative relationship between precipitation and grain growth theoretically. In the present study, by means of the thermodynamics analysis, kinetics calculation, TEM, and SEM, the precipitation behavior of $\mathrm{AlN}$, TiN, MnS, and $\mathrm{Cu}_{2} \mathrm{~S}$ was studied. The pinning force of precipitates and driving force of grain growth were analyzed as well, with the aim to reduce the inhibition effects of precipitates on grain growth, thus enhancing the magnetic properties of CSP process' non-oriented electrical steel.

\section{Materials and Methods}

The main chemical composition of compact strip production (CSP) process non-oriented electrical steel used in the present study is given in Table 1. The continuous casting billet with $70 \mathrm{~mm}$ in thickness, which was soaked at about $1373 \mathrm{~K}$, was hot-rolled to $2.3 \mathrm{~mm}$ in thickness by a six-high rolling mill. The hot bands were cold rolled in $79 \%$ deformation to $0.5 \mathrm{~mm}$ in thickness by a six-high rolling mill. Then, the cold-rolled sheets were annealed at $1093 \mathrm{~K}$ for 2 min in $\mathrm{N}_{2}: \mathrm{H}_{2}=1: 1$ atmosphere for recrystallization and grain growth. The heating rate and cooling rate of the annealing process were $50 \mathrm{~K} / \mathrm{s}$ and $25 \mathrm{~K} / \mathrm{s}$, respectively. The schematic of the thermos-mechanical cycle used in the present study is shown in Figure 1.

Table 1. The main chemical composition of non-oriented electrical steel.

\begin{tabular}{cccccccccc}
\hline Elements & $\mathbf{C}$ & $\mathbf{S i}$ & $\mathbf{M n}$ & $\mathbf{P}$ & $\mathbf{S}$ & Als & $\mathbf{N}$ & $\mathbf{C u}$ & $\mathbf{T i}$ \\
\hline Content, wt $\%$ & 0.0030 & 0.65 & 0.25 & 0.075 & 0.0040 & 0.30 & 0.0035 & 0.030 & 0.0030 \\
\hline
\end{tabular}

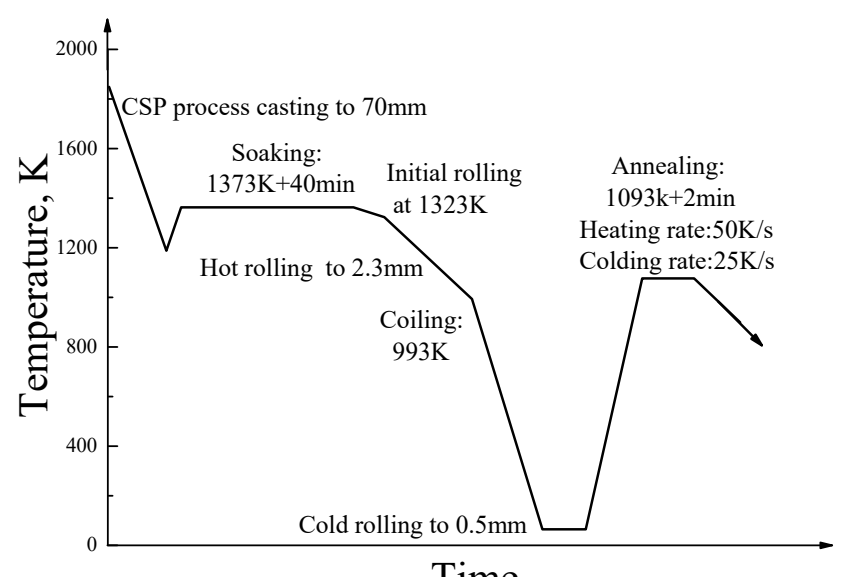

Time

Figure 1. Schematic of the thermos-mechanical cycle used in the present study.

The microstructure and morphology of precipitates in steel were scientifically studied using a transmission electron microscope (TEM; JEM-2100F, JEOL, Tokyo, Japan) and scanning electron microscopy (SEM; Quanta 650FEG, FEI, Morristown, NJ, USA). Combining with energy dispersive 
spectrometer (EDS) and selected area electron diffraction (SEAD), the compositions and morphology of precipitates could be characterized.

The carbon extraction replica test sample for TEM was prepared into a sample with a size of $8 \mathrm{~mm}$ (TD) $\times 10 \mathrm{~mm}(\mathrm{RD})$ by wire cutting and then roughly and finely ground. The samples were prepared by electro-polishing at $90 \mathrm{~mA}$ in $10 \%$ AA electrolyte for $120 \mathrm{~s}$. The electrolyzed samples were coated with a layer of carbon film with a thickness of about $30 \mathrm{~nm}$ using a vacuum carbon spray instrument. After dividing the carbon film into a size of about $2 \mathrm{~mm} \times 2 \mathrm{~mm}$, it was placed in a $10 \%$ perchloric acid alcohol solution for electrolytic release, and then the molybdenum net with $3 \mathrm{~mm}$ in diameter was used to extract the carbon film. The samples were also prepared into SEM samples, and then electropolishing and observation with 100 fields in each sample were done at 3000-10000 magnification under SEM. The size and number of precipitates were analyzed using IPP (Image-Pro Plus, MEDIA CYBERNETICS, Rockville, MD, USA) software.

Magnetic properties of the core losses $\left(\mathrm{P}_{15 / 50}\right)$ were determined at the induction of $1.5 \mathrm{~T}$ and $50 \mathrm{~Hz}$. Magnetic measurements were carried out for final-annealed sheets with $30 \mathrm{~mm}$ in width and $300 \mathrm{~mm}$ in length, both in rolling and transverse directions. The measured values were averaged to parallelize with the Epstein method.

\section{Results and Discussions}

\subsection{Magnetic Properties}

Residual elements (Nb, V, Ti, Cu, etc.), carbon, nitrogen, and sulfur in non-oriented electrical steel would form fine precipitates in the production process [1]. Precipitates would hinder grain growth, which ultimately increases the iron loss and mechanical properties. Meanwhile, precipitates would promote the formation of the $\gamma$-fiber texture and reduce magnetic induction [27]. An important purpose of non-oriented electrical steel slab soaking is to coarsen precipitates, thereby reducing the hazards of the precipitates [5].

The variation tendency between $\mathrm{P}_{15 / 50}$ and $\sum(\mathrm{C}+\mathrm{N}+\mathrm{S}+\mathrm{Ti})$ is shown in Figure 2. As the contents of elements $(\mathrm{Si}, \mathrm{Al}, \mathrm{Mn}, \mathrm{Nb}, \mathrm{V}, \mathrm{Cu}$, etc.) and technology for heating processing were nearly equivalent, the statistical results showed that $P_{15 / 50}$ increased obviously (increase $0.22 \mathrm{~W} / \mathrm{kg}$ ) with an increase of $\sum(\mathrm{C}+\mathrm{N}+\mathrm{S}+\mathrm{Ti})$ in $95-105 \mathrm{ppm}$. It could be speculated that the increase in $\mathrm{P}_{15 / 50}$ was caused by the precipitates formed by $\mathrm{C}, \mathrm{N}, \mathrm{S}$, Ti, etc. Therefore, during the production of non-oriented electrical steel, it is necessary to strictly control the content of magnetic harmful elements. Meanwhile, it is necessary to study the precipitation mechanism of the precipitates and the influence law of the precipitates on the magnetic properties of non-oriented electrical steel.

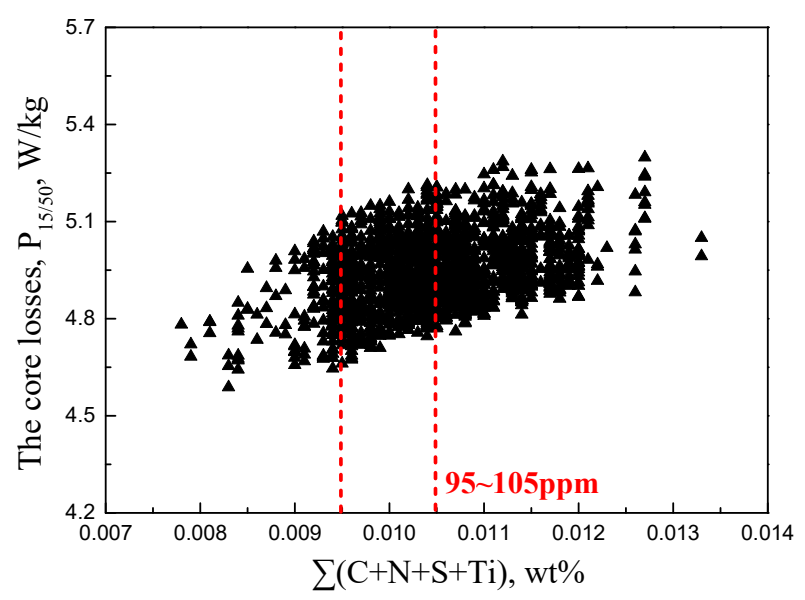

Figure 2. The variation tendency between the core losses $\mathrm{P}_{15 / 50}(\mathrm{~W} / \mathrm{kg})$ and $\sum(\mathrm{C}+\mathrm{N}+\mathrm{S}+\mathrm{Ti})(\mathrm{wt} \%)$. 


\subsection{Morphology and Composition of the Precipitates}

During the smelting and continuous casting process of the CSP process' non-oriented electrical steel, studies have shown that part of fine oxide inclusions could not grow and be absorbed by the ladle slag $[28,29]$. The fine oxide inclusions would remain in the slab, thereby worsening the magnetic properties. In addition, the precipitates would precipitate during production. Because of the rapid cooling process, the CSP process would have a more uniform structure and a smaller degree of segregation of continuous cast slab [1]. Therefore, the segregation in the slab center was ignored in this article. In order to study various inclusions and precipitates in the CSP process' non-oriented electrical steel, the species and size distribution of micro-inclusions and precipitates in samples were analyzed by SEM and TEM. The morphology of typical inclusions and precipitates is shown in Figure 3.
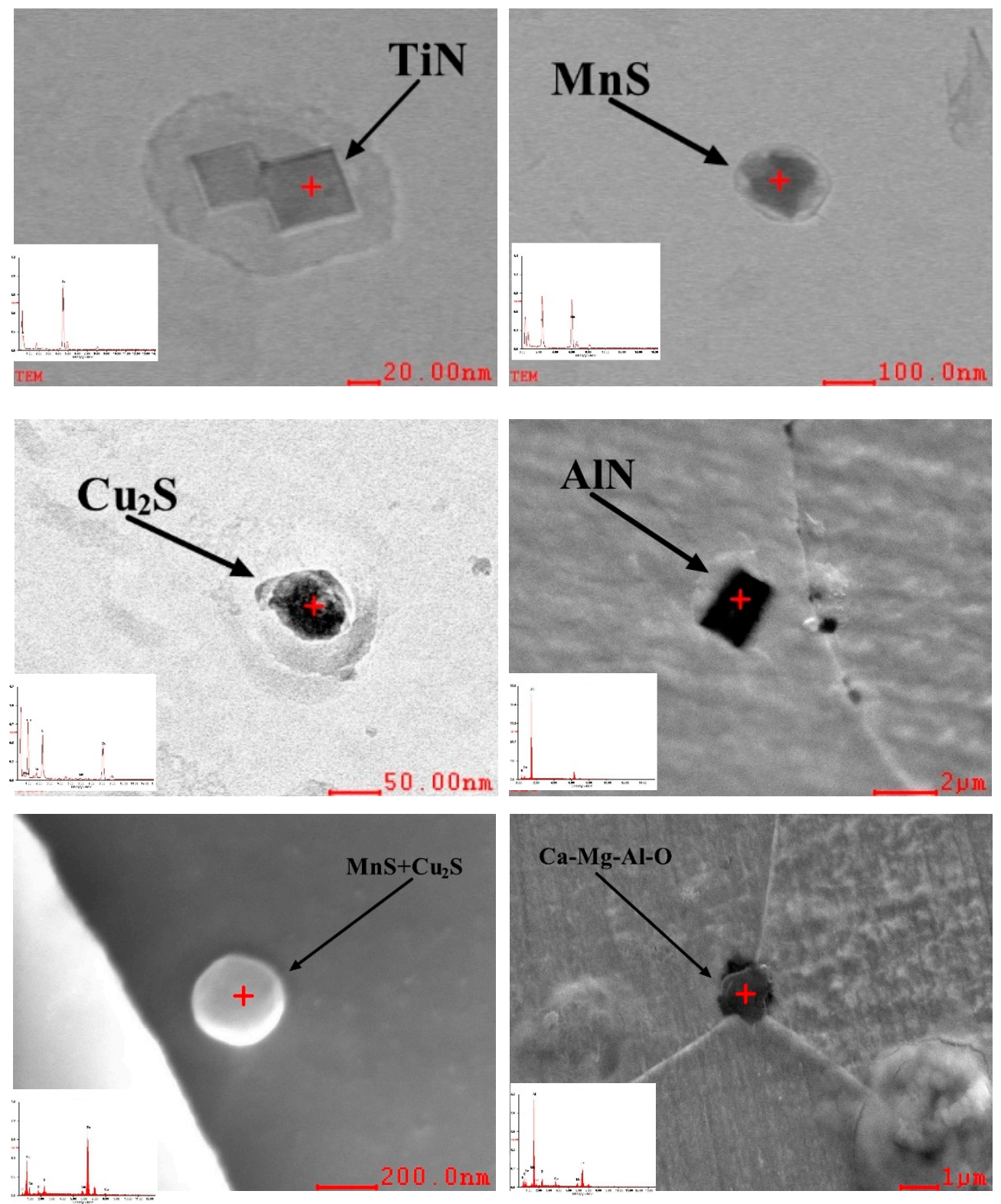

Figure 3. Typical precipitates and inclusions in the annealing sheets.

Figure 3 shows the typical precipitates and inclusions morphology in the annealing sheets. The main precipitates were $\mathrm{AlN}, \mathrm{TiN}, \mathrm{MnS}, \mathrm{Cu}_{2} \mathrm{~S}$, and the composite precipitates. Some fine oxide inclusions were also discovered on the grain boundary. 
Because sulfur is one of the surface-active elements, it tends to segregate to the grain boundary $[14,30]$. During the long time soaking, a number of sulfur atoms segregate along the grain boundary. The diffusion of manganese and copper occurs simultaneously. When the solubility product of manganese, copper, and sulfur supersaturates, $\mathrm{MnS}$ and $\mathrm{Cu}_{2} \mathrm{~S}$ would nucleate at the grain boundaries [31]. Hence, the spherical or quasi-spherical of $\mathrm{MnS}$ and $\mathrm{Cu}_{2} \mathrm{~S}$ are more liable to precipitate along grain boundaries. As AlN and TiN nucleation mode is mainly heterogeneous nucleation $[1,5,8]$, the cubic shape of AlN and TiN precipitates inside grains or grain boundaries.

It is obvious to see that the precipitates are mainly distributed in the grain boundary or in the crystal in Figure 4. Many tiny spherical and blocky precipitates less than $65 \mathrm{~nm}$ were observed throughout the grains and grain boundaries of hot-rolled band and annealed sheets. After counting and measuring the size of precipitates observed in the fields, the size of precipitates in the hot-rolled band and annealed sheets was mainly in the range of 30-500 $\mathrm{nm}$. The precipitate size and density (number of precipitates in the unit area) within $30-500 \mathrm{~nm}$ in all the samples are shown in Figure 5.
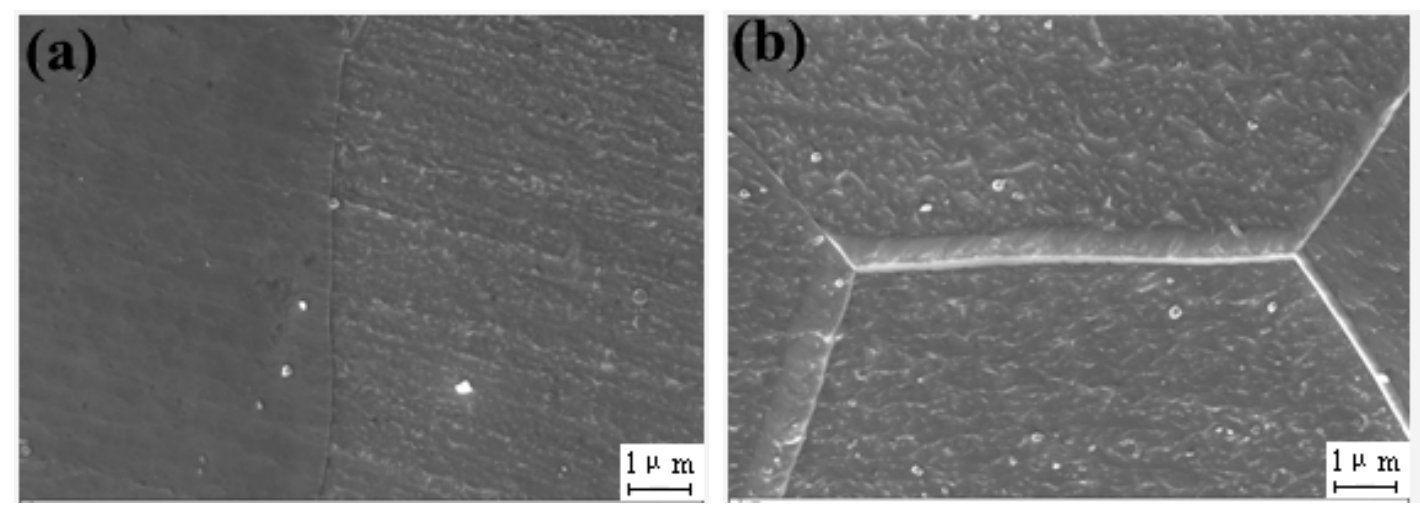

Figure 4. Distribution of precipitates in the hot-rolled band (a) and annealed sheets (b) (SEM).

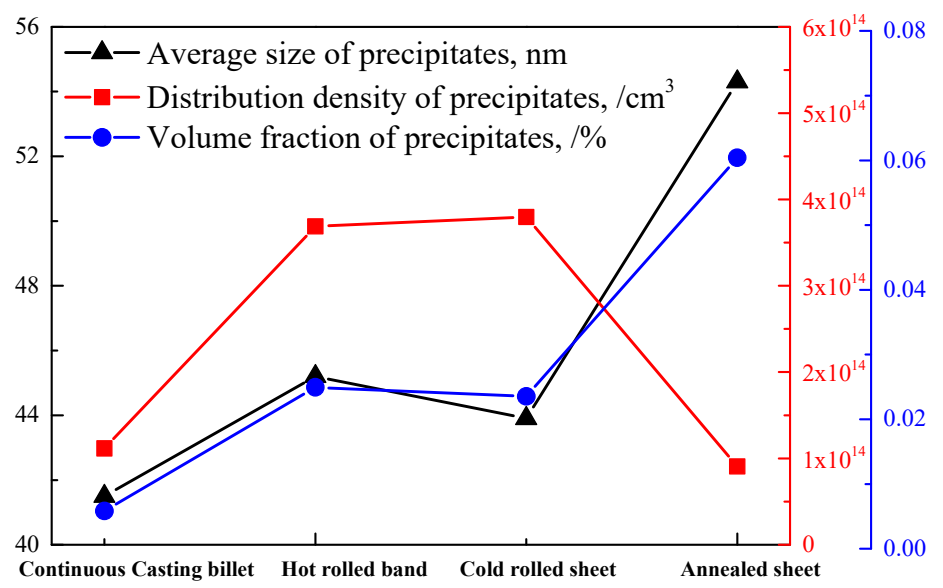

Figure 5. Statistics of precipitates in Continuous Casting billet, hot-rolled band, cold-rolled sheet, and annealed sheet.

As shown in Figure 5, the precipitates in the CSP process' non-oriented electrical steel tended to grow in the whole process. The distribution density and volume fraction of the precipitates before annealing also increased. After annealing, the precipitates further increased in size and volume fraction, but the corresponding distribution density decreased.

Because the cooling rate of the CSP process is fast and the time is short [32], a large number of precipitates had precipitated in continuous casting slab. As precipitates are difficult to precipitate and grow adequately, the average size of precipitates in the continuous casting slab was small [1,5]. Precipitates would further precipitate and grow during the soaking and hot rolling process, so hot-rolled 
bands had fewer fine precipitates than the continuous casting billet. The final annealing process $\left(820^{\circ} \mathrm{C}\right.$, $2 \mathrm{~min}$ ) provided thermodynamic and kinetic conditions for the precipitation and growth of precipitates. The average size, distribution density, and volume fraction further increased after annealing. The main sizes of the precipitates in the annealed sheet mainly distributed in 30-500 $\mathrm{nm}$. The statistical results of the precipitates in the annealed sheets showed that the distribution density, the volume fraction, and the average size of the precipitates were $9.08 \times 10^{13} / \mathrm{cm}^{3}, 0.06 \%$, and $54.3 \mathrm{~nm}$, respectively.

\subsection{Thermodynamic Analysis of Precipitates}

Figure 6 shows the austenite and ferrite phases in non-oriented electrical steel, which were calculated using FactSage 7.2 software (Thermfact/CRCT, Montreal, QC, Canada and GTT-Technologies, Aachen, Germany). The currently investigated non-oriented electrical steel was within the single austenite phase during the soaking at about $1373 \mathrm{~K}$. During the hot rolling process, the initial rolling, finishing rolling, and coiling were within the austenite, ferrite, and ferrite, respectively. The precipitates' precipitation temperature and amount were calculated by FactSage7.2; the results are shown in Figure $6 \mathrm{~b}$. It can be observed that the main precipitates were AlN, MnS, and TiN. The equilibrium precipitation temperature of them was $1479 \mathrm{~K}, 1578 \mathrm{~K}$, and $1588 \mathrm{~K}$, respectively. During soaking at about $1373 \mathrm{~K}$, the precipitation amounts of $\mathrm{AlN}, \mathrm{MnS}$, and TiN under equilibrium conditions were $0.0067 \%, 0.0099 \%$, and $0.0031 \%$, respectively. The equilibrium precipitation amount of MnS and TiN at the soaking temperature of $1373 \mathrm{~K}$ basically reached the upper limit, but that of AlN would increase greatly as the temperature decreased. Therefore, the average size of AlN particles would decrease in the subsequent operation stage. On the contrary, the average size of MnS and TiN would not decrease after soaking.
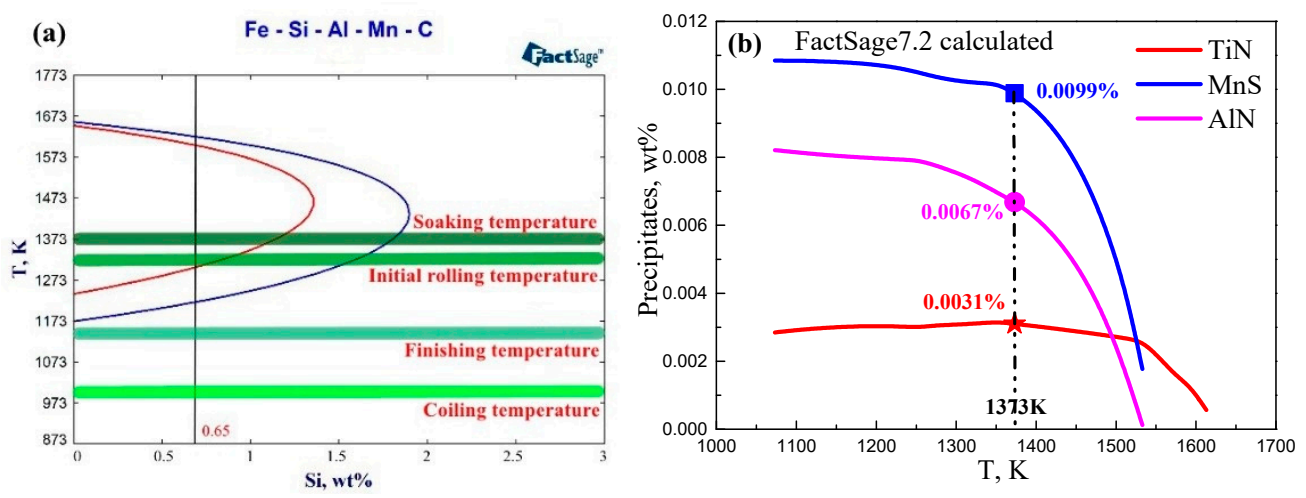

Figure 6. Fe-Si-0.3 wt $\% \mathrm{Al}-0.25 \mathrm{wt} \% \mathrm{Mn}$ phase diagram (a) and precipitation curve of precipitates (b).

The database of FactSage 7.2 does not figure out the relevant data of $\mathrm{Cu}_{2} \mathrm{~S}$, but it would race to precipitate with MnS [1]. In this experiment, because of the single $\gamma$ phase during the soaking at about $1373 \mathrm{~K}$, the solution and precipitation behavior of the $\mathrm{Cu}_{2} \mathrm{~S}$ and $\mathrm{MnS}$ in austenite were mainly discussed. The equilibrium solid solubility product formulas of $\mathrm{Cu}_{2} \mathrm{~S}$ [33] and MnS [34] are Equations (1) and (2).

$$
\begin{gathered}
\lg \{[\mathrm{Mn}] \cdot[\mathrm{S}]\}_{\gamma}=-9020 / T+2.929-(-215 / T+0.097)[\% \mathrm{Mn}] \\
\lg \left\{[\mathrm{Cu}]^{2} \cdot[\mathrm{S}]\right\}_{\gamma}=26.31-44971 / T
\end{gathered}
$$

The equilibrium precipitation temperature of $\mathrm{MnS}$ and $\mathrm{Cu}_{2} \mathrm{~S}$ was $1518.5 \mathrm{~K}$ and $1416.2 \mathrm{~K}$, according to Table 1, as shown in Figure 7, and the precipitation temperature of MnS was very close to the result calculated by FactSage7.2 software. So, it could be speculated that $\mathrm{Cu}_{2} \mathrm{~S}$ would precipitate after $\mathrm{MnS}$. 


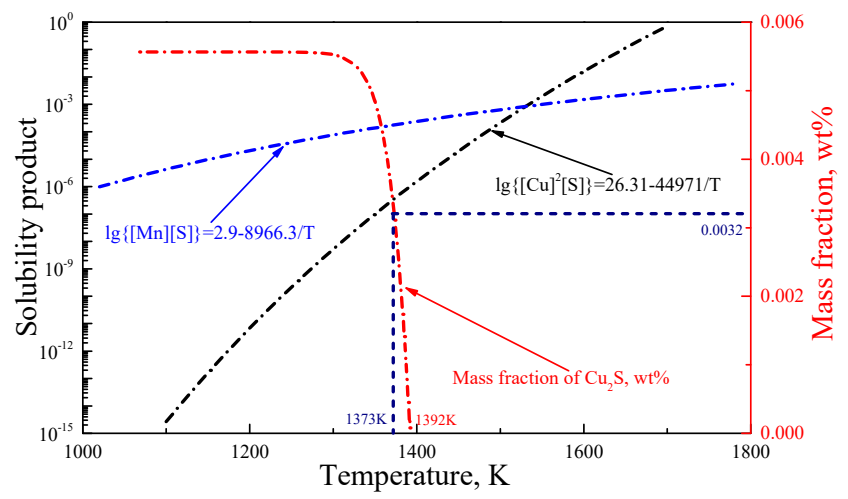

Figure 7. Equilibrium solubility product of $\mathrm{MnS}$ and $\mathrm{Cu}_{2} \mathrm{~S}$ and the precipitation curve of $\mathrm{Cu}_{2} \mathrm{~S}$.

As shown in Figure 7, the decrease of equilibrium solubility product of $\mathrm{Cu}_{2} \mathrm{~S}$ with a decrease in temperature was much greater than MnS. Hence, the equilibrium precipitation temperature of $\mathrm{MnS}$ would gradually approach and be lower than that of $\mathrm{Cu}_{2} \mathrm{~S}$ as the $\mathrm{S}$ content decreased. Calculation by Equations (1) and (2) showed that the solid solubility products of $\mathrm{MnS}$ and $\mathrm{Cu}_{2} \mathrm{~S}$ were equal at $1394.07 \mathrm{~K}$. That is, $\mathrm{Cu}_{2} \mathrm{~S}$ would precipitate below $1394.07 \mathrm{~K}$, and the remaining sulfur was $0.00125 \%$.

As the soaking of the slab is the main stage of precipitation and growth of the precipitates, the equilibrium precipitation amount of each precipitate under soaking is shown in Table 2. As shown in Table 2, the equilibrium precipitation ratios of $\mathrm{MnS}, \mathrm{Cu}_{2} \mathrm{~S}, \mathrm{AlN}$, and $\mathrm{TiN}$ at the soaking temperature were $76.4 \%, 37.2 \%, 65.2 \%$, and $99.3 \%$, respectively. Since the $\mathrm{S}$ element is a grain boundary segregation element $[1,8,14]$, the amount of MnS precipitated on the grain boundary during the soaking process was much larger than that of $\mathrm{Cu}_{2} \mathrm{~S}$. Meanwhile, $\mathrm{AlN}$ and $\mathrm{Cu}_{2} \mathrm{~S}$ precipitated less in the soaking phase. The rest of $\mathrm{AlN}$ and $\mathrm{Cu}_{2} \mathrm{~S}$ would be finely dispersed in the grain boundaries and crystals in the subsequent heat treatment process, which seriously affected the grain growth during the annealing process.

Table 2. Equilibrium precipitation amount at the soaking temperature.

\begin{tabular}{cccccccc}
\hline \multicolumn{2}{c}{ MnS, wt $\%$} & \multicolumn{2}{c}{$\mathbf{C u} \mathbf{2} \mathbf{s}, \mathbf{w t} \%$} & \multicolumn{2}{c}{ AlN, wt $\%$} & \multicolumn{2}{c}{ TiN, wt $\%$} \\
\hline \multirow{2}{*}{ Max } & Equilibrium & Max & Equilibrium & Max & Equilibrium & Max & Equilibrium \\
& 0.0081 & \multirow{2}{*}{0.00623} & 0.00232 & 0.00725 & 0.00473 & 0.00288 & 0.00286 \\
& $(76.4 \%)$ & & $(37.2 \%)$ & & $(65.2 \%)$ & & $(99.3 \%)$ \\
\hline
\end{tabular}

\subsection{Kinetics Analysis of Precipitates}

During the production process of the CSP process' non-oriented electrical steel, the soaking of the slab is the main stage of precipitation and growth of the precipitates. The currently investigated $0.65 \mathrm{wt} \% \mathrm{Si}$ non-oriented electrical steel was within the single austenite phase during the soaking at about $1373 \mathrm{~K}$, as shown in Figure 6. Therefore, the model is based on the following assumptions [8,14]:

1. Assuming the nucleation mode is homogeneous nucleation and grain boundary nucleation;

2. Assuming the nucleus is spherical, and neglecting the misfit or the elastic strain energy between the new phase and the matrix;

3. Assuming the interface of austenite and the new phase attain the partial equilibrium during the precipitation and growth process;

4. Assuming the diffusion of chemical element $\mathrm{M}$, forming the precipitates in the austenite, is the restrictive factor of precipitate's growth. 


\subsubsection{Driving Force for the Nucleation}

The critical nucleus size, $r^{*}$, and the activation energy for nucleation (or the free energy change of formation of the critical nucleus), $\Delta G^{*}$, can be obtained from the following Equations (3)-(5) [8,35-37]

$$
\begin{gathered}
\mathrm{d}_{\text {Homogeneous +Grain boundary nucleation }}^{*}=-\frac{4 \sigma}{\Delta \mathrm{G}_{\mathrm{V}}} \\
\Delta \mathrm{G}_{\text {Homogeneous nucleation }}^{*}=\frac{16 \pi \sigma^{3}}{3\left(\Delta G_{V}\right)^{2}} \\
\Delta \mathrm{G}_{\text {Grain boundary nucleation }}^{*}=A_{1} \times \Delta G^{*}
\end{gathered}
$$

where $A_{1}=\frac{1}{2}\left(2-\frac{3 \sigma_{\mathrm{B}}}{2 \sigma}+\left(\frac{\sigma_{\mathrm{B}}}{2 \sigma}\right)^{3}\right), \sigma_{\mathrm{B}}$ is grain boundary energy $\left(0.73 \mathrm{~J} / \mathrm{m}^{2}\right)[8], \sigma$ is the interfacial energy between the new phase and the matrix, $V m$ is the molar volume of the new phase, $\Delta G_{V}$ is the volume free energy reduction in creating a new phase from the matrix.

The chemical driving power of nucleation and the precipitation process can be represented as Equation (6) [38-40]. [M] $]_{0},[\mathrm{X}]_{0}$ are the initial concentrations of elements $\mathrm{M}$ and $\mathrm{X},[\mathrm{M}],[\mathrm{X}]$ are the equilibrium concentrations of elements $\mathrm{M}$ and $\mathrm{X} . \mathrm{R}$ is the gas constant, and $T$ is the temperature.

$$
\Delta G_{V}=-\frac{R T}{V_{m}}\left[\ln \frac{[M]_{0}}{[M]}+\ln \frac{[X]_{0}}{[X]}\right]
$$

Based on the above equations, the activation energies and the critical nucleus size for $\mathrm{Cu}_{2} \mathrm{~S}$, TiN, AlN, and MnS nucleation can be calculated in austenite during the soaking at about $1373 \mathrm{~K}$. The parameter values for calculation are summarized in Table 3.

Table 3. Parameter values for calculation $[8,33]$.

\begin{tabular}{ccccc}
\hline Phases & Solubility Product & $\begin{array}{c}\text { Diffusion of M, } \mathbf{D}, \\
\mathbf{c m}^{\mathbf{2}} \mathbf{s}\end{array}$ & $\begin{array}{c}\text { Interfacial Energy, } \sigma, \\
\mathbf{J} / \mathbf{m}^{\mathbf{2}}\end{array}$ & $\begin{array}{c}\text { Lattice Constant, } \\
\mathbf{n m}\end{array}$ \\
\hline $\mathrm{AlN}$ & $2.72-10062 / \mathrm{T}$ & $5.9 \exp (-241000 / \mathrm{RT})$ & $1.03504-0.3437 * 10^{-3} \mathrm{~T}$ & $\mathrm{a}=0.3111$, \\
$\mathrm{c}=0.4978$ \\
$\mathrm{TiN}$ & $5.56-17205 / \mathrm{T}$ & $0.15 \exp (-251000 / \mathrm{RT})$ & $1.1803-0.5318 * 10^{-3} \mathrm{~T}$ & 0.4239 \\
$\mathrm{MnS}$ & $2.9-8966.3 / \mathrm{T}$ & $1.7 \exp (-222000 / \mathrm{RT})$ & $0.9225-0.4157 * 10^{-3} \mathrm{~T}$ & 0.52226 \\
$\mathrm{Cu}_{2} \mathrm{~S}$ & $26.31-4971 / \mathrm{T}$ & $0.19 \exp (-272000 / \mathrm{RT})$ & 0.8 & 0.56286 \\
\hline
\end{tabular}

The calculated activation energy and the critical nucleation radius for $\mathrm{Cu}_{2} \mathrm{~S}, \mathrm{TiN}, \mathrm{AlN}$, and $\mathrm{MnS}$ are shown in Figure 8. The critical nucleus size decreased continuously with a decrease in temperature. The critical nucleus size of $\mathrm{Cu}_{2} \mathrm{~S}, \mathrm{TiN}, \mathrm{AlN}$, and $\mathrm{MnS}$ was on the same order of magnitude. The activation energy of each precipitate decreased monotonously with a decrease in temperature. TiN, AlN, and $\mathrm{MnS}$ were nucleated more easily than $\mathrm{Cu}_{2} \mathrm{~S}$ in austenite. $\mathrm{Cu}_{2} \mathrm{~S}, \mathrm{TiN}, \mathrm{AlN}$, and MnS were preferentially nucleated at grain boundaries. 

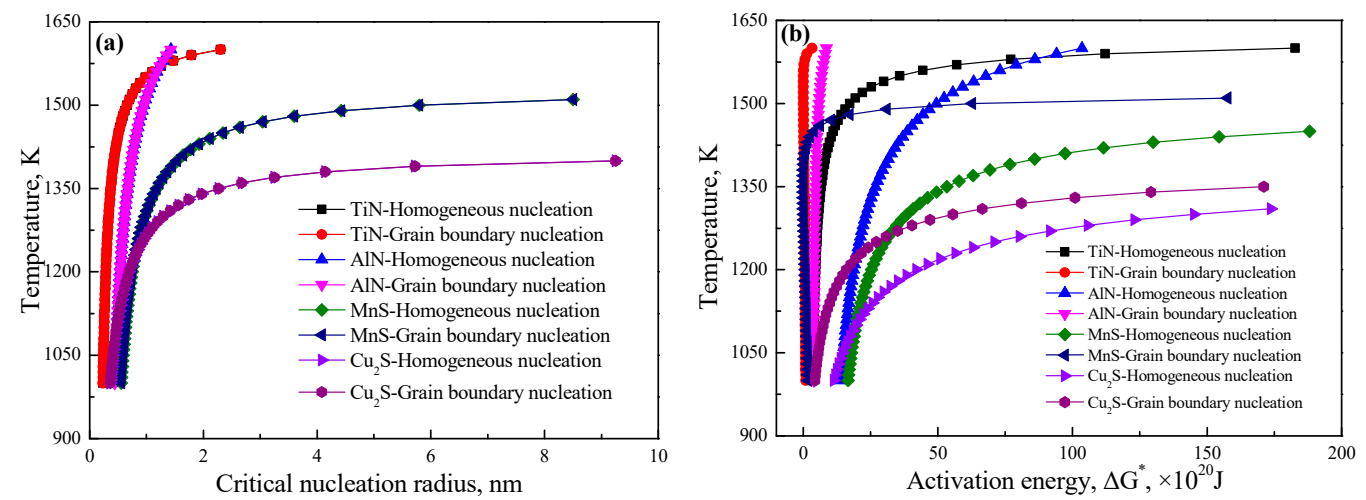

Figure 8. Critical nucleation radius (a) and activation energy (b) for new phases nucleation vs. temperature.

\subsubsection{Nucleation Rate and Precipitation-Time-Temperature}

The homogeneous nucleation rate in the matrix and the heterogeneous nucleation rate on the grain boundary were taken into consideration in the present study. The formula for the relative nucleation rate $(\mathrm{NrT})$ for the homogeneous nucleation and the heterogeneous nucleation on grain boundary could be calculated by Equations (7) and (8), respectively [8].

$$
\begin{gathered}
\lg \left(\frac{I}{K}\right)_{\text {Homogeneous nucleation }}=2 \lg d^{*}+\frac{1}{\ln 10}\left(-\frac{\Delta G^{*}+Q}{k T}\right) \\
\lg \left(\frac{I}{K}\right)_{\text {Grain boundary nucleation }}=2 \lg d^{*}+\lg \frac{\delta}{L}+\frac{1}{\ln 10}\left(-\frac{\Delta G_{g}^{*}+Q_{g}}{k T}\right)
\end{gathered}
$$

where $k$ is the Boltzmann constant $\left(1.3806505 \times 10^{-23} \mathrm{~J} / \mathrm{K}\right), Q$ is the diffusion activation energy of the control element $\mathrm{M}$ in austenite (that is, the diffusion activation energy of a single atom), $\delta$ is the thickness of crystal interface $(0.5 \mathrm{~nm}), L$ is the average grain diameter.

The formula for the precipitation-time-temperature (PTT) diagram for the homogeneous nucleation and the heterogeneous nucleation on grain boundary is calculated by Equation (9) and Equation (10), respectively $[8,41,42]$.

$$
\begin{aligned}
& \lg \left(\frac{t_{0.05 a}}{t_{0 \mathrm{a}}}\right)_{\text {Homogeneous nucleation }}=\frac{2}{3}\left(-1.28994-2 \lg d^{*}+\frac{1}{\ln 10} \times \frac{\Delta G^{*}+2.5 Q}{k T}\right) \\
& \lg \left(\frac{t_{0.05 g}}{t_{0 g}}\right)_{G} \text { rain boundary nucleation }=2\left(-1.28994-2 \lg d^{*}+\frac{1}{\ln 10} \times \frac{A_{1} \Delta G^{*}+Q}{k T}\right)
\end{aligned}
$$

The calculated relative nucleation rate and the precipitation-time-temperature (PTT) diagram for precipitates in austenite are shown in Figure 9. For the heterogeneous nucleation on the grain boundary, $\mathrm{Cu}_{2} \mathrm{~S}, \mathrm{TiN}, \mathrm{AlN}$, and $\mathrm{MnS}$ had low relative nucleation rates compared with homogeneous nucleation. This calculation also implied that the heterogeneous nucleation on the grain boundary of $\mathrm{Cu}_{2} \mathrm{~S}, \mathrm{TiN}, \mathrm{AlN}$, and $\mathrm{MnS}$ might preferentially happen.

The precipitation-time-temperature (PTT) diagram of $\mathrm{Cu}_{2} \mathrm{~S}, \mathrm{TiN}, \mathrm{AlN}$, and $\mathrm{MnS}$ precipitation in the austenite region showed a $\mathrm{C}$-shaped curve. The corresponding precipitation (5\%) nose temperature of $\mathrm{Cu}_{2} \mathrm{~S}, \mathrm{TiN}$, AlN, and MnS was about $1108 \mathrm{~K}, 1453 \mathrm{~K}, 1374 \mathrm{~K}$, and $1243 \mathrm{~K}$ for homogeneous nucleation, $1065 \mathrm{~K}, 1593 \mathrm{~K}, 1584 \mathrm{~K}$, and $1414 \mathrm{~K}$ for grain boundary nucleation, respectively. Hence, TiN, AlN, and MnS were mainly precipitated during the period of soaking at $1373 \mathrm{~K}$, but $\mathrm{Cu}_{2} \mathrm{~S}$ would precipitate slightly. Furthermore, combined with thermodynamic calculation (in Figures 6 and 7), the critical nucleation radius (in Figure 8a), and the activation energy (in Figure 8b) calculation results, it could be confirmed that $\mathrm{TiN}, \mathrm{MnS}$ mainly precipitate during soaking and $\mathrm{AlN}, \mathrm{Cu}_{2} \mathrm{~S}$ would precipitate 
unceasingly with the decrease in the average sizes in the subsequent processes after soaking. The tiny $\mathrm{Cu}_{2} \mathrm{~S}$ in the CSP process' non-oriented electrical steel could also be better understood.
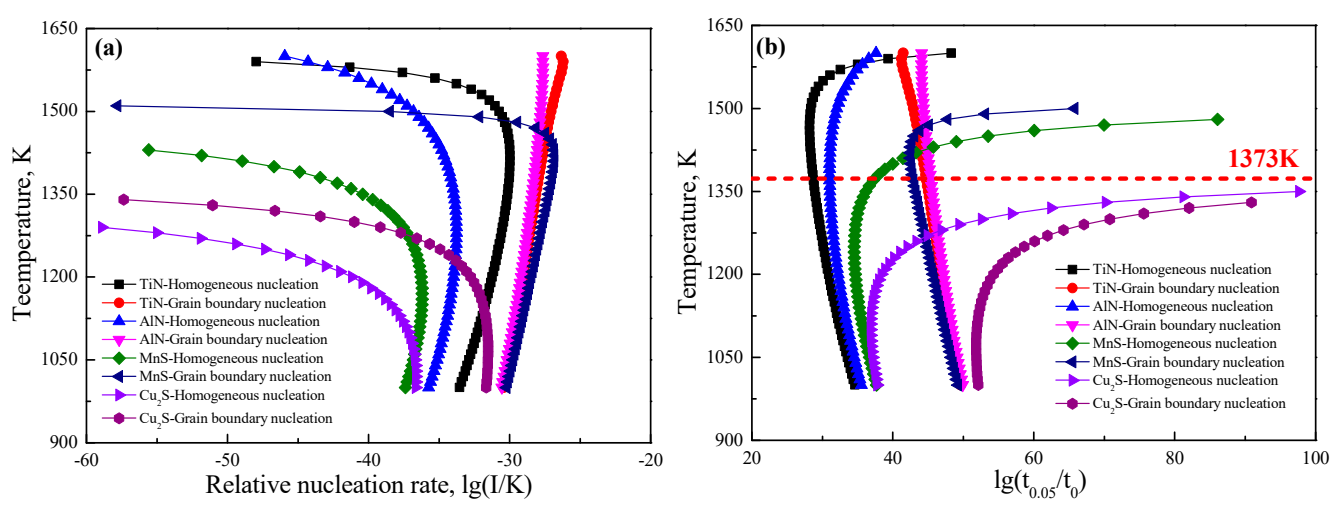

Figure 9. $\operatorname{NrT}(\mathbf{a})$ and PTT (b) curves of new phases precipitated in austenite.

\subsubsection{Growth of Precipitates}

$\mathrm{Cu}_{2} \mathrm{~S}, \mathrm{AlN}$, and TiN control elements of Ostwald ripening are $\mathrm{Cu}, \mathrm{Al}$, and $\mathrm{Ti}$, respectively [8]. However, the precipitation behavior of $\mathrm{MnS}$ in non-oriented electrical steel is more complicated and must be determined first. It can be calculated by Equation (11) [8]. $\omega=A_{\mathrm{Mn}} / A_{\mathrm{S}}$ is the ideal chemical ratio of $\mathrm{MnS}$, and $A_{\mathrm{Mn}}$ and $A_{\mathrm{S}}$ are the relative atomic mass of $\mathrm{Mn}$ and $\mathrm{S}$, respectively.

$$
M n-\omega S=E=\sqrt{\frac{D_{M n-\gamma} \omega}{D_{S-\gamma}} \cdot 10^{2.9-8966.3 / T}} \cdot\left(\frac{D_{S-\gamma}}{D_{M n-\gamma}}-1\right)
$$

The calculation of MnS controlling elements in the precipitation process of non-oriented electrical steel is shown in Table 4. It can be seen that Mn-wS in non-oriented electrical steels was greater than E; hence sulfur would be the controlling element in the Ostwald ripening process of MnS.

Table 4. Controlling element calculation of MnS in non-oriented electrical steel.

\begin{tabular}{cc}
\hline Computational Item & Values \\
\hline Mn- $\omega S$ & 0.243146 \\
$\mathrm{E}$ & 0.026146 \\
Controlling element & $\mathrm{S}$ \\
\hline
\end{tabular}

According to the Fe-Si phase diagram in (Figure 6a), it can be seen that the CSP process' non-oriented electrical steel was in the austenite zone during the soaking process (about $1373 \mathrm{~K}$ ). The change of the average diffusivity of the kinetic control elements for the formation of each precipitated phase with temperature is shown in Figure 10. It can be seen from Figure 10 that the diffusion coefficients of $\mathrm{Al}$ and $\mathrm{S}$ in the $\gamma$-phase were much larger than those of $\mathrm{Ti}$ and $\mathrm{Cu}$. As the temperature decreased, the diffusion capacity of $\mathrm{Al}$ and $\mathrm{S}$ in the $\gamma$-phase decreased, and the rate of decline was linear. As the temperature was less than $1200 \mathrm{~K}$, the diffusion of $\mathrm{Al}, \mathrm{S}, \mathrm{Ti}$, and $\mathrm{Cu}$ in the $\gamma$-phase was almost negligible, and the precipitation kinetic conditions of each precipitate were poor. Therefore, $\mathrm{Cu}_{2} \mathrm{~S}$, TiN, AlN, and MnS would mainly precipitate during soaking at $1373 \mathrm{~K}$. 


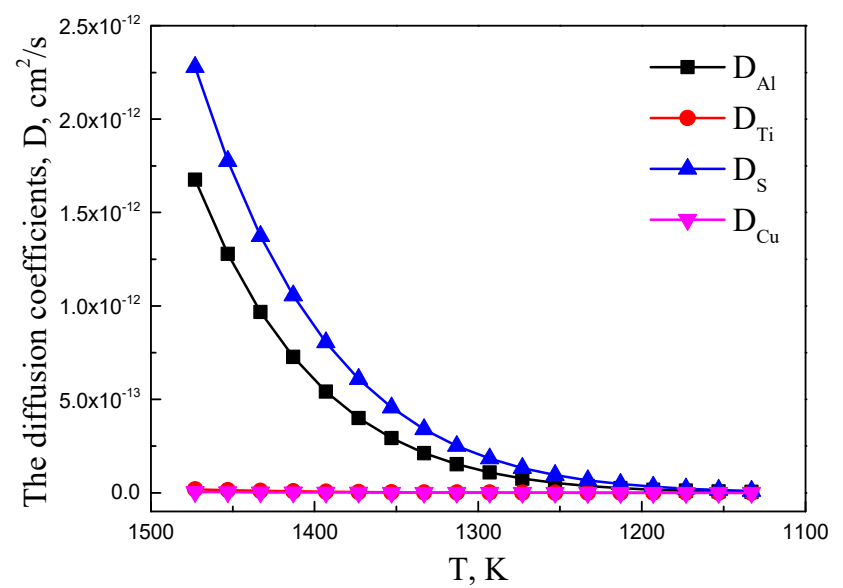

Figure 10. Variation of the diffusion coefficients of control elements with temperature.

After nucleation, particles would mainly grow immediately. Lots of mathematical models have been developed to describe the particle growth in different situations. The theory of size change of the precipitated phase in the dilute solution was first proposed by Ostwald. In the present paper, the Ostwald ripening model of particles during the soaking process (about $1373 \mathrm{~K}$ ) can be described by the following Equation (12) [8]:

$$
\bar{r}_{t} \approx\left(\frac{8 \sigma V_{P}^{2} D C_{0}}{9 V_{B} C_{P} R T}\right)^{\frac{1}{3}} \cdot t^{\frac{1}{3}}
$$

where $C_{0}$ is the equilibrium concentration of an element in the matrix $(\mathrm{mol} / \mathrm{mol}) ; C_{P}$ is the equilibrium molar concentration of an element in the precipitate $(\mathrm{mol} / \mathrm{mol}) ; V_{P}$ is the molar number of precipitate $\left(\mathrm{m}^{3} / \mathrm{mol}\right) ; V_{B}$ is the molar number of austenite $\left(\mathrm{m}^{3} / \mathrm{mol}\right) ; D$ is the average volume diffusion rate of alloy atoms.

The calculated evolution of the particle size with time at $1373 \mathrm{~K}$ in austenite is shown in Figure 11. The average particle size of $\mathrm{Cu}_{2} \mathrm{~S}, \mathrm{TiN}, \mathrm{AlN}$, and $\mathrm{MnS}$ increased with time. The increasing velocity of particles was great at the early stage, and the curve of the increasing velocity tended to even flat along with the reaction proceeding continuously. Due to the higher diffusion coefficient of $\mathrm{S}$ and $\mathrm{Al}$ in austenite during the soaking process, both $\mathrm{MnS}$ and $\mathrm{AlN}$ grew faster than $\mathrm{Cu}_{2} \mathrm{~S}$ and TiN. The growth rate and size of AlN and MnS were much larger than those of $\mathrm{TiN}$ and $\mathrm{Cu}_{2} \mathrm{~S}$, as shown in Figure 11 . After soaking for $40 \mathrm{~min}$, the sizes of $\mathrm{AlN}, \mathrm{MnS}$, TiN, and $\mathrm{Cu}_{2} \mathrm{~S}$ were $105.02 \mathrm{~nm}, 42.72 \mathrm{~nm}, 5.42 \mathrm{~nm}$, and $9.74 \mathrm{~nm}$, respectively.

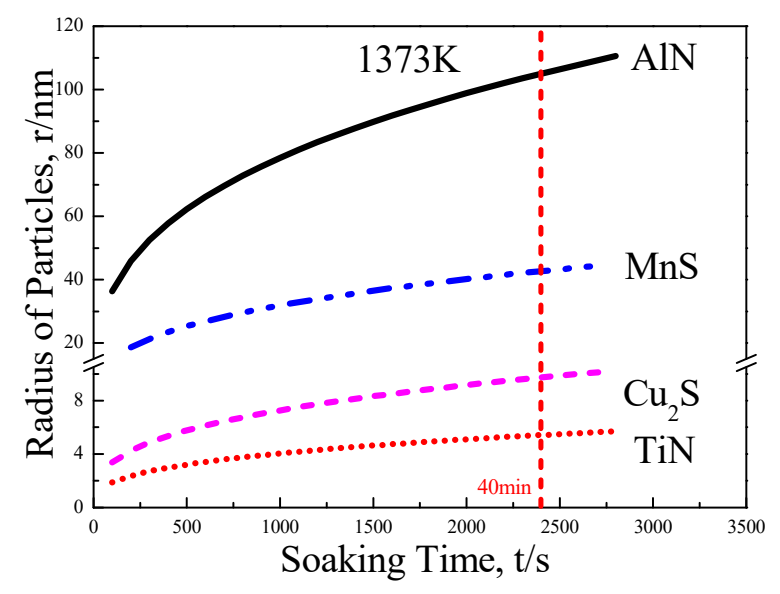

Figure 11. The growth potential of $\mathrm{Cu}_{2} \mathrm{~S}, \mathrm{TiN}, \mathrm{AlN}$, and $\mathrm{MnS}$ in $\gamma$-Fe at $1373 \mathrm{~K}$. 


\subsection{Grain Growth Behavior}

Grain size is controlled by the competition between the driving and pinning forces for grain growth, and grain growth would tend to occur as the driving force exceeds the pinning force [43]. Precipitates in the CSP process' non-oriented electrical steel tended to be stable above the recrystallization temperature, as shown in Figure 5. It can be judged that precipitates would play pinning or dragging action on the grain boundaries at the recrystallization temperature.

The pinning force of precipitates and the driving force of grain growth were discussed in this study. The driving force for grain growth is provided by the reduction of grain boundary energy. The driving force provided by dislocation density on the grain growth could be negligible in non-oriented electrical steel. A theoretical equation modified by Gladman [44] could be used for calculating the driving force, $F_{\mathrm{d}}$, for grain growth, as shown in Equation (13). The pinning effect of precipitates on grain growth is caused by the reduction in grain boundary areas. The pinning force, which was analyzed by Zener formula, rigid boundary model (RBM), and flexible boundary model (FBM), is shown by Equations (14) and (16) $[14,45,46]$, with the hypotheses that the grain growth will stop by the pinning force of particles.

$$
\begin{gathered}
F_{\mathrm{d}}=\left(\frac{3}{2}-\frac{2}{Z}\right)\left(\frac{\gamma}{R}\right) \\
F_{\text {Zener }}=\frac{3 \sigma \cdot f}{2 D} \\
F_{R B M}=\frac{6 \sigma \cdot f}{\pi \cdot r} \\
F_{F B M}=\frac{3 \sigma \cdot f^{2 / 3}}{\pi \cdot D}
\end{gathered}
$$

where $F_{\mathrm{d}}$ is the driving force, $f$ is the volume fraction of particles, $D$ is the average radius of the grains, $\mathrm{Z}$ is the size advantage (the ratio of the maximum grain size to the average grain size), and $\gamma$ and $\sigma$ are the grain boundary energy per unit area (taken as $0.8 \mathrm{~J} / \mathrm{m}^{2}$ ) [47].

The values of the pinning force of precipitates and the driving force of grain growth were calculated and listed in Table 5, and the trend of $F_{\mathrm{d}}$ with grain size (R-critical) is shown in Figure 12. The pinning forces were calculated by Zener formula, rigid boundary model (RBM), and flexible boundary model (FBM) and showed that the precipitates in the annealed sheet of 30-500 nm would pin grain growth at different grain sizes. The pinning force caused by $100-300 \mathrm{~nm}$ particles was the largest and by $70-100 \mathrm{~nm}$ was the second. Hence, the $100-300 \mathrm{~nm}$ particles played the main role in hindering grain growth, as shown in Figure 12. It can be concluded that a few finer grains, which have a much larger driving force, can grow up, and a large amount of grains is impeded by the precipitates.

Table 5. The calculated pinning forces $(F p)$ of precipitates-annealed sheet samples.

\begin{tabular}{ccccccc}
\hline Size, $\mathbf{n m}$ & $\mathbf{D} / \mathbf{n m}$ & Number/cm $^{\mathbf{3}}$ & $\mathbf{f} / \%$ & $\boldsymbol{F} \boldsymbol{p}$ (Zener)/Pa & $\boldsymbol{F} \boldsymbol{p}$ (RBM)/Pa & $\boldsymbol{F} \boldsymbol{p}$ (FBM)/Pa \\
\hline $30-70$ & 34 & $6.53 \times 10^{13}$ & $1.88 \times 10^{-3}$ & $6.64 \times 10^{4}$ & $8.45 \times 10^{4}$ & $3.42 \times 10^{5}$ \\
$70-100$ & 75 & $1.89 \times 10^{13}$ & $5.85 \times 10^{-3}$ & $9.36 \times 10^{4}$ & $1.19 \times 10^{5}$ & $3.31 \times 10^{5}$ \\
$100-300$ & 188 & $6.31 \times 10^{12}$ & $3.07 \times 10^{-2}$ & $1.96 \times 10^{5}$ & $2.50 \times 10^{5}$ & $3.99 \times 10^{5}$ \\
$300-500$ & 345 & $2.39 \times 10^{11}$ & $7.19 \times 10^{-3}$ & $2.50 \times 10^{4}$ & $3.19 \times 10^{4}$ & $8.26 \times 10^{4}$ \\
$500-1000$ & 702 & $3.42 \times 10^{10}$ & $8.67 \times 10^{-3}$ & $1.48 \times 10^{4}$ & $1.89 \times 10^{4}$ & $4.59 \times 10^{4}$ \\
$1000-3000$ & 1823 & $1.37 \times 10^{9}$ & $6.09 \times 10^{-3}$ & $4.01 \times 10^{3}$ & $5.10 \times 10^{3}$ & $1.40 \times 10^{4}$ \\
\hline
\end{tabular}




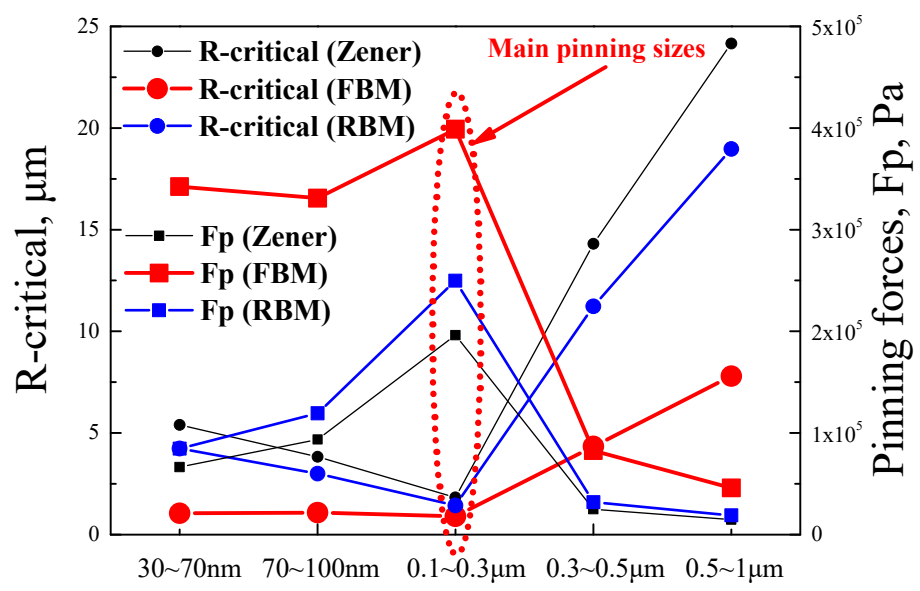

Figure 12. Relationship between Fd and R-critical.

\section{Conclusions}

The precipitation behavior and effect on grain growth of precipitates in the CSP process' non-oriented electrical steel were characterized experimentally and theoretically. The conclusions would guide scholars, reducing the effects of precipitates and enhancing the magnetic properties of the CSP process' non-oriented electrical steel. The following results were obtained:

1. As the contents of elements and technology for heating processing are nearly equivalent, $P_{15 / 50}$ increases obviously with an increase in $\sum(\mathrm{C}+\mathrm{N}+\mathrm{S}+\mathrm{Ti})$ in 95-105 ppm.

2. TEM and SEM results show that the main particles are $\mathrm{AlN}, \mathrm{TiN}, \mathrm{MnS}, \mathrm{Cu}_{2} \mathrm{~S}$, and fine oxide inclusions. The distribution density, the volume fraction, and the average size of the precipitates in the annealed sheets are $9.08 \times 10^{13} / \mathrm{cm}^{3}, 0.06 \%$, and $54.3 \mathrm{~nm}$, respectively.

3. Theoretical calculations show that precipitates are preferentially nucleated at grain boundaries. During the soaking process, TiN and MnS are the main precipitates, and $\mathrm{AlN}$ and $\mathrm{Cu}_{2} \mathrm{~S}$ would precipitate continuously, and the average particle size of $\mathrm{AlN}$ and $\mathrm{Cu}_{2} \mathrm{~S}$ particles decreases in the subsequent process after soaking.

4. Combined with SEM and theoretical calculation results, the average size of $\mathrm{AlN}$ and $\mathrm{Cu}_{2} \mathrm{~S}$ particles would decrease after soaking, but that of MnS and TiN is the opposite.

5. The precipitates in 30-500 $\mathrm{nm}$ would hinder the grain growth during annealing, and the 100-300 nm particles played the main role in hindering the grain growth.

Author Contributions: Formal analysis, methodology, investigation, resources, data curation, and writing, J.-1.Q.; validation, L.X., F.-h.G.; project administration and funding acquisition, S.-t.Q.; software, J.-w.H., H.-j.W. All authors have read and agreed to the published version of the manuscript.

Funding: This research was funded by the National key research and development plan, grant number 2016YFB0300305.

Acknowledgments: Financial supports from the National key research and development plan (2016YFB0300305) and FactSage 7.2 software of Anhui University of Technology are gratefully acknowledged.

Conflicts of Interest: The authors declare no conflict of interest.

\section{References}

1. He, Z.Z.; Zhao, Y.; Luo, H.W. Electrical Steel; Metallurgical Industry Press: Beijing, China, 2012.

2. Xu, Y.; Jiao, H.T.; Qiu, W.Z.; Misra, R.D.K.; Li, J.P. Relative effect(s) of texture and grain size on magnetic properties in a low silicon non-grain oriented electrical steel. Materials 2018, 11, 1161. [CrossRef]

3. Mehdi, M.; He, Y.; Hilinski, E.J.; Edrisy, A. Effect of skin pass rolling reduction rate on the texture evolution of a non-oriented electrical steel after inclined cold rolling. J. Magn. Magn. Mater. 2017, 429, 148-160. [CrossRef] 
4. Alcantara, F.L.; Barbosa, R.; Cunha, M.A. Study of aluminum nitride precipitation in Fe-3\% Si steel. Mater. Res. 2013, 16, 1039-1044. [CrossRef]

5. Xiang, L.; Yue, E.B.; Fan, D.D.; Qiu, S.T.; Zhao, P. Calculation of AIN and MnS Precipitation in Non-Oriented Electrical Steel Produced by CSP Process. J. Iron Steel Res. Int. 2008, 15, 88-94. [CrossRef]

6. Luo, Y.; Conejo, A.N.; Zhang, L.F.; Chen, L.F.; Cheng, L. Effect of Superheat, Cooling Rate, and Refractory Composition on the Formation of Non-metallic Inclusions in Non-oriented Electrical Steels. Metall. Mater. Trans. B 2015, 46, 2348-2360. [CrossRef]

7. Nakayama, T.; Honjou, N. Effect of aluminum and nitrogen on the magnetic properties of non-oriented semi-processed electrical steel sheet. J. Magn. Magn. Mater. 2000, 213, 87-94. [CrossRef]

8. Yong, Q.L. Secondary Phases in Steel; Metallurgical Industry Press: Beijing, China, 2006.

9. Yashiki, H.; Kaneko, T. Effects of $\mathrm{Mn}$ and $\mathrm{S}$ on the grain growth and texture in cold rolled $0.5 \%$ Si steel. ISIJ Int. 1990, 30, 325-330. [CrossRef]

10. Boca, I.; Czirakib, A.; Grofc, T. Analysis of Inclusion in Cold Rolled Non-Oriented Si-Fe Strips. J. Magn. Magn. Mater. 1990, 83, 381. [CrossRef]

11. Luo, Y.; Zhang, L.F.; Li, M.; Sridhar, S. A Thermodynamic Model to Estimate the Formation of Complex Nitrides of $\operatorname{AlxMg}(1-x) \mathrm{N}$ in Silicon Steel. Metall. Mater. Trans. B 2018, 49, 894-901. [CrossRef]

12. Li, F.J.; Zhang, F.; Li, H.G.; Zhao, D.; Zheng, S.B. Study on the Mechanism of Sulfur Compound Precipitates of Non-Oriented Silicon Steel. In Proceedings of the 144th Annual Meeting E Exhibition, TMS 2015; Springer International Publishing: Cham, Switzerland, 2015; pp. 827-832.

13. Wu, Y.; Li, F.J.; Wang, T.; Zhao, D.; Huang, H.F.; Li, H.G.; Zheng, S.B. Influence of $\mathrm{Cu}_{2} \mathrm{~S}$ precipitates dissolution on ferrite grain growth during heat treatment in the non-oriented electrical steel sheet. Met. Mater. Int. 2017, 23, 618-624. [CrossRef]

14. Li, F.L.; Li, H.G.; Wu, Y.; Zhao, D.; Peng, B.W. Effect of precipitates on grain growth in non-oriented silicon steel. J. Mater. Res. 2017, 32, 1-8. [CrossRef]

15. Chen, Y.L.; Wang, Y.; Zhao, A.M. Precipitation of AlN and MnS in Low Carbon Aluminium-Killed Steel. J. Iron Steel Res. Int. 2012, 19, 54-59. [CrossRef]

16. Sun, N.; Patterson, B.R.; Suni, J.P.; Weiland, H. Characterization of particle pinning potential. Acta Mater. 2006, 54, 4091-4099. [CrossRef]

17. Hansen, S.S.; Sande, J.B.V.; Cohen, M. Niobium carbonitride precipitation and austenite recrystallization in hot-rolled microalloyed steels. Metall. Trans. A Phys. Metall. Mater. 1980, 11, 387-402. [CrossRef]

18. Karasev, A.V.; Suito, H. Effect of Particle Size Distribution on Austenite Grain Growth in Fe-0.05mass \%C Alloy Deoxidized with Mn-Si, Ti, Mg, Zr and Ce. ISIJ Int. 2006, 46, 718-727. [CrossRef]

19. Titov, A.O.; Ryo, I.; Hideaki, S. Grain-Growth-Inhibiting Effects of TiC and ZrC Precipitates in Fe-0.15 0.30mass\%C Alloy. ISIJ Int. 2008, 48, 301-309. [CrossRef]

20. Jams, J.; Karasev, A.; Nakajima, K.; Sivananthan, S. Effect of Secondary Nitride Particles on Grain Growth in a Fe-20 mass\% Cr Alloy Deoxidised with Ti and Zr. ISIJ Int. 2013, 53, 476-483.

21. Skromme, B.J.; Zhang, Y.; Smith, D.J. Growth and characterization of pseudomorphic single crystal zinc blende MnS. Appl. Phys. Lett. 1995, 67, 2690. [CrossRef]

22. Fan, L.F.; Xu, X.Y.; Yue, E.B. Analysis on the Inclusion in Continuous Casting Slab of High-Grade Non-Oriented Silicon Steel. Wide Heavy Plate 2007, 13, 21-23.

23. Guo, Y.Y.; Cai, K.K. Study on Microinclusoins in Cold-Rolled Non-Oriented Silicon Steel Sheet. J. Chin. Rare Earth Soc. 2004, 22, 498-502.

24. Yano, K.; Honda, A.; Obara, T. Non-Oriented Silicon Steel Sheet and Method. US Patent No.5676771, 14 October 1997.

25. Zhang, F. Change of Inclusions and Grain Growth of Silicon Steels by Adding Ca Alloy During RH Refining Process. Electr. Eng. Mater. 2013, 82, 28-32.

26. Wang, B.M.; Zhao, Z.Y.; Chen, L.F.; Huang, S.; Luo, W.B.; Zheng, F.F. Principal component regression analysis on the size and quantity of inclusions affecting magnetic properties of non-oriented silicon steel. Metall. Anal. 2014, 34, 1-6.

27. Arita, Y.; Ushigami, Y. Effect of Aluminum and Titanium Content on Grain Growth, Texture and Magnetic Properties in 3\%Si Non-Oriented Electrical Steel. Mater. Sci. Forum. 2007, 539-543, 4428-4433. [CrossRef]

28. Hu, Z.Y.; Ren, Q.; Zhang, L.F. Evolution of oxide inclusions in W800 non-oriented electrical steel. J. Iron Steel Res. 2018, 30, 282-287. 
29. Luo, Y.; Zhang, L.F.; Chen, L.F.; Hu, Z.Y. Evolution of Inclusions During RH Refining in Non-Oriented Electrical Steel. In Proceedings of the 13th China Electrical Steel Academic Conference, Beijing, China, 16 July 2015.

30. Heiple, C.R.; Roper, J.R.; Stagner, R.T. Surface active element effects on the shape of GTA, laser and electron beam welds. Weld. J. 1983, 72, 62.

31. Zhang, Z.; Lin, Q.; Yu, Z. Grain boundary segregation in ultra-low carbon steel. Mater. Sci. Eng. A 2000, 291, 22-26. [CrossRef]

32. Tian, N.Y. Thin Slab Continuous Casting and Rolling Process; Metallurgical Industry Press: Beijing, China, 1998.

33. Liu, Z.Z.; Kobayashi, Y.; Nagai, K. Crystallography and Precipitation Kinetics of Copper Sulfide in Strip Casting Low Carbon Steel. ISIJ Int. 2004, 9, 1560-1567. [CrossRef]

34. Wriedt, H.A.; Hu, H. The solubility product of manganese sulfide in 3 pct silicon-iron at 1270 to $1670 \mathrm{~K}$. Metall. Matr. Trans. A 1976, 7,711-718. [CrossRef]

35. Yong, Q.L.; Bai, A.M.; Gan, Y. Ostward Ripening of Second-Phase Particle in Dilute Solution-II. Analytic Solution. J. Iron Steel Res. 1992, 4, 59.

36. Dong, T.L.; Liu, R.; Yue, E.B.; Qiu, S.T.; Zhao, P. Kinetics of Precipitation for MnS in 3 \%Silicon Steels. J. Iron Steel Res. 2010, 22, 44-47.

37. Wang, H.J.; Fu, B.; Xiang, L.; Qiu, S.T. Nucleation mechanism of precipitate of AlN in ferrite phase of Hi-B steel. J. Iron Steel Res. 2015, 27, 43-48.

38. Zhang, K.; Sun, X.J.; Zhang, M.Y.; Li, Z.D.; Ye, X.Y.; Zhu, Z.H.; Huang, Z.Y.; Yong, Q.L. Kinetics of (Ti, V, Mo) C Precipitated in $\gamma / \alpha$ Matrix of Ti-V-Mo Complex Microalloyed Steel. Acta Metall. Sin. 2018, 54, 1122-1130.

39. Fang, F.; Yong, Q.L.; Yang, C.F.; Zhang, Y.Q. Precipitating Kinetics of V(C, N) in Ferrite of V-N Microalloying Steel. Acta Metall. Sin. 2009, 45, 625-629.

40. Peng, N.Q.; Tang, G.B.; Liu, Z.D.; Yong, Q.L. Quantitative calculation on precipitation behavior of complex microalloyed carbonitride during hot rolling. Trans. Mater. Heat Treat. 2011, 32, 157-163.

41. Christian, J.W. Equilibrium and General Kinetic Theory; Pergamon Press: Oxford, UK, 1975.

42. Xu, Z.; Zhao, B.C. Principle of Phase Transition in Solid Metal; Science Press: Beijing, China, 2004.

43. Mason, J.K. Grain boundary energy and curvature in Monte Carlo and cellular automata simulations of grain boundary motion. Acta Mater. 2015, 94, 162-171. [CrossRef]

44. Gladman, T. On the theory of the effect of precipitate particles on grain growth in metals. Proc. R. Soc. Lond. Ser. A Math. Phys.Sci. 1966, 294, 298-309.

45. Smith, C.S. Grains, phases, interfaces: An interpretation of microstructure. Trans. Metall. Soc. AIME 1948, $175,15-51$.

46. Deardo, A.J.; Ratz, G.A.; Wray, P.J. Thermomechanical processing of microalloyed austenite. In Proceedings of the International Conference on the Thermomechanical Processing of Microalloyed Austenite; Metallurgical Society of AIME: Pittsburgh, PA, USA, 1982.

47. Chapa, M.; Medina, S.F.; López, V.; Femández, B. Influence of $\mathrm{Al}$ and $\mathrm{Nb}$ on optimum Ti/N ratio in controlling austenite grain growth at reheating temperatures. ISIJ Int. 2002, 42, 1288-1296. [CrossRef]

(C) 2020 by the authors. Licensee MDPI, Basel, Switzerland. This article is an open access article distributed under the terms and conditions of the Creative Commons Attribution (CC BY) license (http://creativecommons.org/licenses/by/4.0/). 